\title{
The daily work of Lean leaders - lessons from manufacturing and healthcare
}

\author{
Bozena Poksinska, Dag Swartling and Erik Drotz
}

\section{Linköping University Post Print}

\section{Tweet}

N.B.: When citing this work, cite the original article.

This is an electronic version of an article published in:

Bozena Poksinska, Dag Swartling and Erik Drotz, The daily work of Lean leaders - lessons from manufacturing and healthcare, 2013, Total Quality Management and Business Excellence.

Total Quality Management and Business Excellence is available online at informaworldTM: http://dx.doi.org/10.1080/14783363.2013.791098

Copyright: Taylor \& Francis (Routledge): SSH Titles http://www.routledge.com/ 


\author{
The daily work of Lean leaders - lessons from manufacturing and healthcare \\ Bozena Poksinska, Dag Swartling and Erik Drotz \\ Division of Quality Technology and Management, Linköping University, Sweden
}

Keywords: Lean leadership, Lean production, leadership behaviours, managerial tasks

Paper Type: Research paper

\begin{abstract}
The aim of this paper is to contribute to a better understanding of managerial practices and leadership in Lean organisations. The results presented in this paper are based on five case studies. The manager's role changed radically with the implementation of Lean production. The focus in managerial tasks changed from managing processes to developing and coaching people. Supporting structures were developed to empower employees and give them more responsibility for daily management activities. These supporting structures included visual control, goal deployment, short daily meetings, two-way communication flow, and a system of continuous improvement. Many leadership behaviours exhibited by Lean managers can be classified as transformational leadership behaviours. However, the need for transformational leadership behaviours was smaller, if the supporting management structure was strong.
\end{abstract}

\title{
Introduction
}

Many organisations nowadays are interested in adopting Lean production practices to improve their productivity, reduce costs and enhance competitive advantage (Lewis, 2000). The term Lean production was coined by Krafcik (1988) and popularized by Womack, Jones and Roos in their book The Machine that Changed the World (1990). The authors aimed to explain the productivity differences between Japanese and Western automakers and used the term "Lean production" to describe the superiority of the Toyota production system, which requires less human effort, less space, less capital, less material, less inventory, and less time to make a greater and growing variety of products with fewer defects (Womack et al., 1990). Lean production is no longer exclusive to the automotive industry, but is widely applied in other industry sectors including service (see e.g. Cuatrecasas, 2004; Alsmadi et al., 2012; Suarez-Barraza et al., 2012) and healthcare (see e.g. Miller, 2005; Lummus et al., 2006; Fillingham, 2007). The concept is often described as an integrated socio-technical system whose main objective is to eliminate waste and reduce operational costs (Ohno, 1988; Shah and Ward, 2007). However, since the meaning of Lean production has been shaped and reshaped over time, there is a lack of a uniform definition today (Hines et al., 2004; Pettersen, 2009).

Although the key tools of Lean production are relatively easy to grasp and implement in different contexts (Womack and Jones, 1996), in reality many organisations are not able to transform themselves into Lean enterprises (Liker, 2004; Bhasin and Burcher, 2006). Many Lean improvement programs yield promising results initially, but fail to sustain them over time (Mann, 2005; Hines et al., 2008). Several organisations reporting significant gains from Lean implementation also found that the improvements remain localized to the specific unit 
and they are unable to transfer the learning to other parts of the organisation (Adler and Cole, 2000).

Why are sustainable Lean transformations so difficult to achieve? Several authors emphasize that successful implementation of Lean production requires a change in the culture of an organization (see e.g. Liker, 2004; Mann, 2005; Bhasin and Burcher, 2006; Dahlgaard et al., 2011). The key factor in creating and changing organisational culture is leadership (Schein, 2010). Mann (2005) states that the primary reason for the failure of many Lean initiatives might be the inability to change leadership practices. Lean production requires a different approach to management and leadership, a change in the way a manager acts, interacts and communicates with workers and makes decisions (Liker, 2004; Mann, 2005; Hines et al., 2008). There is a growing realisation of the importance of leadership in Lean transformation (Spear, 2004; Hines et al., 2008), but few studies (see e.g. Liker and Convis, 2011) have empirically investigated and described Lean leadership. Publications found in this area (see e.g. Emiliani, 1998; Flinchbaugh et al., 2008; Mann, 2009) have weak connection to theory or are often based on "common sense". There is a need for research-based studies that provide a deeper understanding of Lean leadership and Lean management practices and position them in relation to contemporary leadership theory. The aim of this paper is therefore to contribute to a better understanding of leadership and managerial practices in Lean organisations. The primary research questions that were addressed in this study are as follows: What are the characteristics of Lean leadership, including role, style and behaviours of Lean leaders? What are the structures, mechanisms, operational tools, and methods to manage Lean organisations and develop employees? How is Lean leadership connected with contemporary leadership theory?

\section{Theoretical background}

\section{Leadership and Management}

The term "leadership” can be conceptualized in many different ways. However, according to Northouse (1997) some common themes can be identified that are central to the phenomenon of leadership. These themes are: leadership is a process; leadership involves influence; leadership occurs within a group context, and leadership involves goal attainment (Northouse, 1997). In the literature there is also considerable debate over the differences between "managers" and "leaders" (Yukl, 1997). Kotter (1990) states that management and leadership are two distinct functions. The primary function of management is to control and coordinate various activities, whereas the primary function of leadership is to produce change and movement. Like Yukl (1997), we see management and leadership as two distinct processes, but leaders and managers are not necessarily different persons. Managerial work may imply both a social influence process (commonly assigned to leadership) while providing a structure to the work of individuals (management task). Leadership exists at every level throughout an organization, and usually includes management tasks (Northouse, 1997). In this paper we consider both leadership and management activities and do not separate the roles of leaders and managers.

\section{Lean leadership}

In a recent publication, Liker and Convis (2011) present a leadership model describing the most important characteristics of Toyota leadership. The model consists of four stages: 1. Commit to Self-Development; 2. Coach and Develop Others; 3. Support Daily Kaizen and 
4. Create Vision and Align Goals. We discuss the four stages of the model below and relate them to viewpoints and experiences of the other authors writing about Lean leadership.

The first stage implies that Lean leaders need to have a strong commitment to self-development and must develop themselves first before they can take responsibility for teaching others the philosophy. The most important values of the Toyota philosophy, known as the True North values, are the spirit of challenge, kaizen, genchi genbutsu, teamwork and respect for humanity. According to Emiliani (2008), Lean leadership needs to be supported by Lean beliefs that drive certain behaviours and over time result in managerial competencies. Liker (2004) also emphasizes that Toyota leaders have both in-depth understanding of the work and the ability to develop and lead people, and are respected for both their technical knowledge and leadership abilities.

The second stage is about coaching and developing others. The Lean leaders are expected to teach employees the values and cultural norms of the organisation, which means they must understand and live the culture. They should encourage, promote and enable organisational learning and knowledge sharing (Mann, 2005). The culture must support the employees doing the work (Liker, 2004) and be characterized by trust, shared responsibility, and openness to experimentation without fear of failure (Mann, 2005). Some authors state that effective Lean leadership involves behaviours that foster participation and employee empowerment (Emiliani, 1998; Found and Harvey, 2007). Lean leaders do not solve problems themselves, but instead ask employees questions to encourage them to think problems through for themselves (Liker, 2004; Spear, 2004).

The third stage is about supporting daily kaizen and encouraging participation and engagement for improvement activities (Liker and Convis, 2011). The same aspect is emphasized by Spear (2004) and Found (2007), who state that the leader's role is to help workers understand the responsibility of improving their own operations and to provide necessary resources to enable the improvement work. A Lean leader needs to develop an ability to be a facilitator who actively engages with employees and encourages them to contribute ideas and continuously learn (Mann, 2005). Since the workforce at Toyota is organised in teams, an important role of Lean leaders is to support teamwork (Found and Harvey, 2007; Liker and Convis, 2011).

Finally, the fourth stage implies creating True North vision, which can be described as the organisation's philosophical objective and long-term improvement goals. Goals supporting the True North vision are set at all managerial levels and aligned to action and improvement initiatives (Flinchbaugh et al., 2008; Liker and Convis, 2011).

Lean leadership needs to be supported by Lean managerial practices and tools (Liker and Convis, 2011). According to Mann (2005), a Lean management system consists of four principal elements: leader standard work, visual controls, daily accountability processes, and discipline. Leader standard work specifies activities that appear as daily routine, e.g., gemba walk or review status of performance measures (Liker and Convis, 2011). Visual control is a system of signs, information displays, and work organisational tools that are designed to manage and control the processes and that provide immediate understanding of a situation or condition (Mann, 2005; Liker and Convis, 2011). Daily accountability is about a meeting structure aiming to ensure follow-up on task assignments made in response to emerging problems or opportunities for improvement. The meetings usually have fixed times and 
durations and follow a standardized agenda. Finally, discipline is necessary to execute the first three elements as designed and intended (Mann, 2005).

\section{Lean leadership and leadership theory}

The available publications on Lean leadership are often disconnected from leadership theory and present it as something unique and distinct. The authors however see many similarities with contemporary leadership theories such as transformational leadership, servant leadership and leadership in self-managed teams. Therefore these theories will be briefly presented in this section.

Transformational and servant leadership theories are according to Avolio et al. (2009) the most frequently researched theories over the past 20 years. Transformational leadership was first discussed in a more political context by Burns (1978) and later applied to the organizational context by Bass (2006). Transformational leadership is defined in terms of the leader's influence on followers. According to Bass (1999), leaders motivate followers by doing the following: 1) making them more aware of the importance of specified goals; 2) getting them to transcend their own self-interest for the sake of the team or the organisation; and 3) activating their higher-order needs. Transformational theory includes two distinct types of leadership behaviours: transactional and transformational. Transformational leaders have been characterized by four components: idealized influence, inspirational motivation, intellectual stimulation, and individualized consideration. In contrast, transactional leaders are characterized by contingent reward and management by exception (Bass and Riggio, 2006).

The servant leadership theory was developed by Greenleaf in the 1970s and is based on the idea that a leader is a servant. The primary objective of servant leaders is to serve and meet the needs of others, which should be the fundamental motivation for leadership (Greenleaf and Spears, 2002). Servant leadership is related to transformational leadership and there is a debate as to whether there are any differences between these two theories (Stone et al., 2004). Both transformational leadership and servant leadership emphasize the consideration and appreciation of individuals, the importance of teaching, coaching, developing, and empowering followers (Stone et al., 2004). According to Bass (2000), servant leadership goes beyond transformational leadership in selecting the needs of others as a leader's highest priority. Most importantly, transformational leaders strive to align their own and others' needs with the needs of the group or organization. Servant leaders on the contrary focus on the needs of the followers, helping them to develop and grow as persons (Bass, 2000).

There is a growing trend in organisations to give more responsibility for daily activities to teams rather than individuals (Yukl, 1997). Teams with a multi-skilled workforce are the fundamental work unit in Lean organisations (Liker, 2004) and the principles behind the teamwork have a strong connection to the concept of self-managed teams. In self-managed teams there are two types of leaders: internal leaders who coordinate team activities, and external leaders who support the team's self-management (Yukl, 1997). The role of an external leader has been a central focus in research on self-managed teams (see e.g. Stewart and Manz, 1995) and is often described as a coach, facilitator, and educator. Several authors (see e.g. Yukl, 1997; Carte et al., 2006) emphasize that in the case of self-managed teams we have to pay attention to shared leadership, which focuses on the various roles, internal 
dynamics, and relationships of team members. Stewart and Manz (1995) proposed a model where a different pattern of leader behaviour is used depending on the stage of team development. Similarly, Carew et al. (1986) discuss the Situational leadership model (Blanchard et al., 1993) in relation to different stages of group development. The authors suggest that different leadership styles designated as directing, coaching, supporting, and delegating should be used depending on the team's development stage (Carew et al., 1986).

\section{Research Methodology}

The results presented in this paper are based on five case studies performed in organisations that are regarded as successful Lean organisations. The case organisations represent a mix of manufacturing company, healthcare organisations and municipal elderly care unit. The primary interest of the study was in Lean leadership practices in healthcare organisations. However, since Lean production in healthcare is a relatively new phenomenon and none of the healthcare cases seemed to be a mature Lean organisation, an initial study was done in a mature Lean manufacturing company. The manufacturing case served as a reference point for defining Lean leadership practices and was therefore studied more in-depth. The empirical evidence was collected through interviews, observations, participation in meetings and studies of company documents (Merriam, 1998). In the manufacturing case the empirical data was additionally collected by following managers' everyday work (McDonald, 2005). For more details about the case organisations and data collection methods see Table 1.

Table 1 - Case organisations

\begin{tabular}{|c|c|c|}
\hline Cases & Short description & Data collection methods \\
\hline $\begin{array}{l}\text { Manufacturing } \\
\text { company }\end{array}$ & $\begin{array}{l}\text { Biopharmaceutical } \\
\text { company producing } \\
\text { drugs }\end{array}$ & $\begin{array}{l}\text { First study in 2009: } \\
11 \text { interviews (factory manager, production manager, first-line } \\
\text { managers, operators) } \\
\text { Observations } \\
\text { Participation in meetings } \\
\text { Document studies } \\
\text { Second study in 2011: } \\
\text { Shadowing } 4 \text { managers (factory manager, production manager, } 2 \\
\text { first-line managers) } \\
6 \text { interviews (the same managers as above and } 2 \text { operators) }\end{array}$ \\
\hline $\begin{array}{l}\text { Municipal } \\
\text { elderly care }\end{array}$ & $\begin{array}{l}\text { Unit } \\
\text { providing municipal } \\
\text { elderly care }\end{array}$ & $\begin{array}{l}8 \text { interviews (Lean facilitator, quality manager, managers for } \\
\text { elderly care, elderly care employees) } \\
\text { Participation in meetings } \\
\text { Document studies }\end{array}$ \\
\hline Care centre 1 & $\begin{array}{l}\text { Primary care centre } \\
\text { with approx. } 25 \\
\text { employees }\end{array}$ & $\begin{array}{l}6 \text { interviews (care unit manager-doctor, } 2 \text { doctors, } 3 \text { nurses) } \\
\text { Participation in meetings } \\
\text { Document studies }\end{array}$ \\
\hline Care centre 2 & $\begin{array}{l}\text { Primary care centre } \\
\text { with approx. } 35 \\
\text { employees }\end{array}$ & $\begin{array}{l}8 \text { interviews (care unit manager - physiotherapist, } 4 \text { doctors, } 2 \\
\text { nurses, secretary) } \\
\text { Document studies }\end{array}$ \\
\hline Hospital unit & $\begin{array}{l}\text { Physiology unit } \\
\text { with approx. } 20 \\
\text { employees }\end{array}$ & $\begin{array}{l}10 \text { interviews (care unit manager - doctor, } 2 \text { doctors, } 1 \text { nurse, } 2 \\
\text { secretaries, } 4 \text { biomedical analysts) } \\
\text { Document studies }\end{array}$ \\
\hline
\end{tabular}

The interviews were semi-structured and took about one to two hours depending on the interviewee. The interview questions focused on four main areas: how Lean production is defined and perceived by the organisation; how Lean production was implemented; how the improvement work is organized; and how the roles and responsibilities of managers and 
employees have changed after Lean production was implemented. Both managers and their subordinates were interviewed (for details see Table 1). All interviews were taped and transcribed (Kvale, 1996).

Participant observations were made at several meetings such as group improvement meetings, cross-functional improvement meetings, and management meetings. The empirical data from the meetings was collected using structured field notes (DeWalt and DeWalt, 2002). The researchers used an observational template, which contained a number of questions such as who is leading the meeting, who participates, what is the agenda, what objects are used, who is making decisions and what performance measures are used. If a phenomenon appeared that couldn't be coded by using the template, additional notes were taken.

In the manufacturing company case, four managers were followed over two consecutive working days. This method implied shadowing a person from the moment she/he begins the working day until she/he leaves for home. During the shadowing the researchers asked clarification questions and wrote field notes to document the answers and observations. At the end of the shadowing period a structured interview with questions around the observations was conducted (McDonald, 2005).

Finally, several company documents such as strategies, documented procedures and instructions were analysed using qualitative content analysis (Merriam, 1998).

The data collection methods were combined to offer multiple data sources. Data collection and analysis were carried out by a research team in order to achieve complementary insights and enhanced confidence in the findings (Eisenhardt, 1989). A draft summary of the principal findings was presented at a feedback session with key respondents. The purpose of this session was the validation of the results, and it was seen as a possibility to expand the analysis through collaboration, elaboration, reaction, and the development of alternate and multiple interpretations of the findings (Merriam, 1998).

\section{Findings}

We focus primarily on four managerial processes as defined by Yukl (1997): 1) developing and maintaining relationships; 2) getting and giving information; 3) making decisions; and 4) influencing people. These processes are interwoven among managerial activities and there might be an overlap between the different categories.

\section{Developing and maintaining relationships}

Our results show that the manager's role changed radically with the implementation of Lean production. Before Lean production was launched the primary task of managers was to monitor and control processes with respect to planned objectives and customer requirements. They managed the operations from offices and mainly interacted with employees when problems appeared. As the Lean improvement program was introduced, managers became more visible in the daily work and their primary task became to support their employees. Both formal and informal meetings with employees increased and became more important. The managers started to walk around the organisations just to chat with employees and participated more frequently in coffee breaks. They have also given positive recognition of a job well done and provided constructive feedback more often. All these activities had the purpose of increasing employee motivation and organizational commitment. 
The changed manager's role also implied that managers started to delegate responsibilities and coach employees in ways that nurtured their growth and brought out their creativity, knowledge, and experience to support the organization's goals. Coaching implied that managers perceived their employees as resources to be developed and expanded. The managers didn't solve problems themselves, but passed this responsibility to employees and worked as facilitators in the problem-solving process. Several new development opportunities were created for employees and implied taking new roles in the organisation. The managers have recognized that their role is to be facilitators and coaches, and not simply controllers.

\section{Getting and giving information}

Another important change was increased two-way communication and focus on establishing information flow from bottom-up to top-down. Instead of just informing by email, documents, and information boards, the information was passed on in various short meetings. The meetings used a standardized agenda and were aimed at receiving direct feedback from employees. The agenda implied planning daily activities, checking the conditions to meet the day's demands, reviewing objectives and discussing different problems of daily work. The purpose was also to develop an understanding of current goals and strategies and to involve employees in improving quality, efficiency, and safety.

In the case of the manufacturing company, four goals (quality, safety, delivery and economy) were controlled daily and communicated at all levels of the organization. The goals were first reviewed in the morning meeting at the team level and displayed in three different colours: green, yellow and red. The team managers relayed these further at the morning meeting to the flow manager, who in turn communicated them to the next managerial level. If any of the goals were red, which indicated some kind of problem, immediate actions were taken.

In healthcare organisations the team working that day made a review of the day's operations and discussed problems from the previous day. Since the case organisations in healthcare had flat managerial structures, reporting to higher managerial levels was not practiced.

All case organisations developed means for visual control and communication. Simple visual tools were used to clarify the goals and to give timely feedback on process performance. Different whiteboards displayed information with simple charts and standardized colour codes providing instant and visually stimulating information. The aim was to give employees a high degree of ownership in their work by making information available and easier to understand.

An example of visual management in a healthcare context was visualization of patient waiting times at Physiology unit and Care centre 1 . Waiting times are a common problem in Swedish healthcare and reducing them is the primary goal of many Lean improvement programs. The visualization of waiting times aimed to promote a deeper level of understanding of the problem and align efforts towards accomplishing improvement activities. Healthcare staff felt more in control of the problem and could quickly identify when something was going wrong or not happening.

In all five cases whiteboards supporting the daily improvement work were developed. The improvement boards usually included two parts: first, some means for submitting 
improvement ideas (place for Post-it notes, reflection book, improvement idea form) and second, visualization of current improvement initiatives. Regular meetings were held at whiteboards to review the progress of the improvement work and plan for new activities.

The workplaces in all case organisations were equipped with visual aids enabling an individual to immediately recognize the standard and avoid mistakes. This could be a manual for operating equipment or standardized treatment trolleys.

\section{Making decisions}

In the period of Lean implementation, managers were under pressure, since they were responsible not only for controlling performance, but also for coaching individuals and driving implementation activities and improvement work forward. As the Lean implementation progressed employees were empowered and more involved in decision making. The first step was involving employees in improving daily operations. All case organisations developed supporting structures and routines to enable problem-solving and improvement activities as part of the everyday work. Employees were encouraged to submit improvement ideas and made responsible for planning and realization of improvements. They had freedom to make decisions and take appropriate actions to realize planned improvements. Furthermore, in all cases employees received increased responsibility for managing and controlling daily operations and took over many managerial assignments such as monitoring and updating performance measures or performing audits. In the case of the manufacturing company, operators received special roles as e.g. spec operator (operator who partly took over team manager's role, i.e., became internal team leader), quality operator, safety operator, etc. In the public sector (healthcare units and municipal elderly care) where the process orientation was weak, several core processes were identified and mapped. Process teams with process owners were created and made responsible for the daily management and improvement of those processes. The main tasks of managers became to support and coach their employees. The stress levels for managers decreased as the new responsibilities of employees became a routine.

\section{Influencing people}

Since a successful Lean transformation relies on the active involvement of the entire organization, an important role of the Lean manager was also to communicate and teach Lean philosophy and principles. Many means for developing Lean culture have already been mentioned in the previous sections. Managers served as role models and acted in ways consistent with the organizational values and culture. They provided support for continuous improvement and demonstrated their own willingness to embrace change. Attention was paid to developing trust and collaboration, fostering interactions and sharing information. The managers focused more on individual employee's skills, experience and abilities and set challenges that would nurture and encourage growth in the individual. By communicating objectives and sharing values and principles, the managers influenced employees' attitudes towards Lean production and encouraged appropriate behaviours.

Managers controlled, measured, and rewarded performance aspects that reflected the values and contributed to fulfilment of current goals. In all case organisations the primary objective of Lean implementation was building a culture of continuous improvement, where employees are empowered to eliminate waste and drive improvements. Managers systematically paid attention to activities that supported continuous improvement. 
Continuous improvement became an agenda item in meetings and improvement activities were monitored and visualized. Time and resources were allocated to enable continuous improvement. Managers gave recognition for submitting improvement ideas and active participation in the realization of improvements. In the case of the manufacturing company, first individual employees and, as the system matured, the teams had an objective to submit a certain number of improvement ideas per year.

\section{Cross-case analysis of manufacturing and healthcare organizations}

The manufacturing company was the most mature Lean organisation. Most of the Lean tools were in place and the culture was deeply rooted in the employees' minds. Although the case organisations from the public sector didn't yet achieve the same maturity in their Lean journey, we observed many similar trends and patterns of development.

The manufacturing company already had a process-oriented, team-based organization at the point when the decision was made to introduce a Lean improvement program. The implementation of Lean production brought a change towards more self-managed teams. In 2009 the first-line managers still acted as internal and external leaders for the teams (Stewart and Manz, 1995). Then the responsibility for managing daily operations was gradually passed to operators. In the follow-up study in 2011 the internal leaders' role was taken over by a team member called "spec operator" and the teams were self-directed.

In the healthcare cases process orientation and teamwork were new ways of working. The Lean implementation therefore first implied changes towards a more process-oriented organisation. New procedures, responsibilities and tools needed to be developed to provide a support for the process-based teamwork. The value streams were identified and mapped and teams responsible for managing and improving them were created. Although the healthcare cases were not yet at that level of maturity, they have shown a similar change trend with self-managed teams and internal leaders working in the processes. The managerial tools such as visual control, short daily meetings, and two-way communication flow also played an increasingly important role in the daily management of the healthcare units, although they still left considerable potential for development.

There were also some differences in the development to Lean leadership in the case organisations. The organisational structure of the manufacturing case included several managerial levels, which were involved in the Lean implementation work and demonstrated strong support and commitment. Hoshin Kanri and daily management including all managerial levels were an important characteristic of the Lean management system at the manufacturing company. In contrast, the healthcare cases were isolated islands in the bigger healthcare structure. The Lean improvement programs were started locally by the managers of the healthcare units. There was only one managerial level involved in implementing Lean and there was a lack of commitment and vision from superiors. The managers were in a difficult situation, arguing for Lean production at higher managerial levels and tackling the challenges of implementing the improvement program in the organisation. The supporting structure and culture for continuous improvement was much weaker and the successes of the improvement program strongly dependent on the managers' ability to keep employees committed and motivated. The managerial tools such as Hoshin Kanri and management by objective played a very limited role in the healthcare cases. 


\section{Discussion}

This section will discuss the empirical findings from the perspective of contemporary leadership theory. First, the authors see a connection between Lean leadership and transformational leadership. Our results show that the focus in the managerial work changed from managing operations to managing people. Essentially, the primary role of transformational leaders is to develop the motivation and to lead employees not by power of position, but by personal influence and concern for individual needs and development (Bass and Riggio, 2006). This was also the primary role of Lean leaders. The components of Lean leadership such as empowering employees, participation in goal achievement, and focus on learning and personal responsibility are important transformational leadership aspects. Many actions exhibited by the managers in case organisations could be classified as transformational leadership behaviours. Transformational leadership is measured using the Multifactor Leadership Questionnaire (MLQ) (Bass and Riggio, 2006). The items included in the questionnaire describe in a good way the characteristics of Lean leadership, such as: "I create enthusiasm for a task" and "I encourage others to develop their abilities". This was also confirmed by Emiliani (2003) who states that many Lean leader competencies can be characterized as transformational. An interesting aspect is that the need for transformational leadership behaviours decreased as the Lean management system matured. In the beginning the implementation process was characterized by managerial push, which means that the success of the improvement program was dependent on the management's actions (Shiba et al., 1993). The managers focused their actions primarily on motivating people, which required strong transformational leadership skills and behaviours. When the Lean managerial practices have been developed and employees accepted their new roles, the need for transformational leadership practices decreased and the managerial push was replaced by employee pull.

Second, as already pointed out by Sugimori (1977), Lean production is the "respect-for-human system" where the workers are entrusted with greater responsibility and authority and allowed to display their capabilities through active participation in the workplace improvement. The case organisations were examples of sustainable Lean implementation, where much attention was given to employees. The management actions focused on providing conditions for employee development, growth and empowerment. The primary responsibility of managers became to support and coach employees, which is reminiscent of the theory of servant leadership (Greenleaf and Spears, 2002). Some authors present an inverted pyramid, where Lean managers are at the bottom of the organisational hierarchy (Found and Harvey, 2007; Liker and Convis, 2011). This inverted pyramid aims to illustrate that the primary role of managers is to serve and meet the needs of others, which is in accordance with the theory of servant leadership.

Third, Lean leadership has a connection to the concept of self-managed teams. Team leadership is central for Lean production, where work is organised in teams. The case organisations reorganized their work and moved towards a team-based organisation. Teams were responsible for performing tasks in their part of the flow and were the focal point of problem solving and improvement. The management responsibility was gradually passed to team members. This type of shared leadership in Lean organisations is one of the means to realize participation, empowerment, and the utilization of employees' skills (Stewart and Manz, 1995). Stewart and Manz (1995) state that in order to develop self-managed teams the 
managers need to change their role from supervisor to facilitator, which was confirmed by this research study. Liker (2004, p.188) describes that the situational leadership model taught by Blanchard was used at Toyota to develop their work teams. Work groups go through different development stages before they can progress to high performing teams. Different leadership approaches are needed at different stages of team development (Carew et al., 1986). Our results show that in the early stage of setting up self-managing teams, high involvement of external leaders with strong transformational leadership skills is required. The use of a transformational leadership style has been shown to encourage team self-management (Williams et al., 2010). The authors state that transformational leadership aspects, such as focus on individual development, involvement in decision making and participation in improvement activities, foster greater team self-management. The case of the manufacturing company shows however that once self-regulation mechanisms for the team are developed, the need for active leadership decreases.

\section{Conclusions}

The implementation of Lean production in the five case organisations implied changed roles for managers. The focus in managerial tasks changed from managing processes to managing people. The primary role of managers was now to motivate, coach and develop individuals and teams. The case organisations became more process-oriented and the team became the primary operational unit for managing and improving processes. The responsibility for the daily management of activities was gradually passed to teams. The change towards self-managed teams was a long-term process, which required a sustained investment of effort and resources. The managers focused on empowering employees to take control of their work process and involve them in improvement activities. The means and methods to achieve higher employee empowerment and involvement included visual control, short daily meetings with a standardised agenda, two-way communication flow, and building a system of continuous improvement.

This study connects Lean leadership with contemporary leadership theories. First, Lean leadership is related to transformational leadership. To develop employees and encourage cooperation and responsibility the managers used a coaching leadership style, which shows many similarities with transformational leadership. This style of management implied helping employees discover their own talents and skills and facilitating the problem-solving and improvement processes. Second, Lean leadership shares underlying principles with servant leadership. In traditional companies the management hierarchy may be drawn as a pyramid, similar to an organization chart, with the CEO at the top, and the operators at the base. The principle is that directions are given from the top, in a command and control manner. This study shows that the hierarchy pyramid in Lean organisations becomes inverted with managers at the base and employees at the top. Managers pay much attention to employees' needs and their development and the managerial work is focused on creating a learning and facilitative work environment. Third, Lean leadership has a connection with leadership in self-managed teams. As the Lean implementation matured the teams became more self-managed and the managerial tasks started to be shared between the first-line manager and the internal team leader. Internal leaders together with teams were responsible for managing daily activities and first-line managers just stayed responsible for providing direction and support to teams. 
Our results confirm that Lean leadership is a central aspect in implementing and sustaining a Lean improvement program. Without continuous effort from managers the Lean transformation couldn't be achieved. In the beginning the implementation activities were very dependent on managerial push. The most important management task was to influence people, which required strong transformational leadership skills and behaviours. Managers led by example and acted as "culture carriers" to implement the Lean program. As the case organisations developed a solid management system, the need for transformational leadership behaviours was smaller and managers simply needed to act according to the principles and values of the system and culture. Therefore, an important aspect for achieving sustainable Lean improvements is to build a supporting culture and system that guides the behaviour and thinking of the employees. Then the managerial push will be replaced by employee pull and the system will continue without dependence on the individual leader.

\section{References}

Adler, P. and R. Cole (2000). "Designed for learning: a tale of two auto plants." Sloan Management Review 34(3): 85-94.

Alsmadi, M., A. Almani and R. Jerisat (2012). "A comparative analysis of Lean practices and performance in the UK manufacturing and service sector firms." Total Quality Management \& Business Excellence 23(3-4): 381-396.

Avolio, B. J., F. O. Walumbwa and T. J. Weber (2009). "Leadership: Current theories, research, and future directions." Annual Review of Psychology 60: 421-449.

Bass, B. M. (1999). "Two decades of research and development in transformational leadership." European Journal of Work and Organizational Psychology 8(1): 9-32.

Bass, B. M. (2000). "The future of leadership in learning organizations." Journal of Leadership \& Organizational Studies 7(3): 18-40.

Bass, B. M. and R. E. Riggio (2006). Transformational Leadership: Industrial, Military and Educational Impact. Mahwah, NJ: Lawrence Erlbaum.

Bhasin, S. and P. Burcher (2006). "Lean viewed as a philosophy." Journal of Manufacturing Technology Management 17(1): 56-72.

Blanchard, K. H., D. Zigarmi and R. B. Nelson (1993). "Situational Leadership ${ }^{\circledR}$ after 25 years: A retrospective." Journal of Leadership \& Organizational Studies 1(1): 21-36.

Burns, J. M. (1978). Leadership. New York: Harper \& Row.

Carew, D. K., E. Parisi-Carew and K. H. Blanchard (1986). "Group development and situational leadership: A model for managing groups." Training \& Development Journal 40(6): 46-50.

Carte, T. A., L. Chidambaram and A. Becker (2006). "Emergent leadership in self-managed virtual teams." Group Decision and Negotiation 15(4): 323-343.

Cuatrecasas, L. (2004). "A lean management implementation method in service operations." International Journal of Services Technology and Management 5(5): 532-544. 
Dahlgaard, J. J., J. Pettersen and S. M. Dahlgaard-Park (2011). "Quality and lean health care: A system for assessing and improving the health of healthcare organisations." Total Quality Management \& Business Excellence 22(6): 673-689.

DeWalt, K. M. and B. R. DeWalt (2002). Participant Observation: A Guide for Fieldworkers: Lanham, MD: AltaMira Press.

Eisenhardt, K. (1989). "Building theories from case study research." Academy of Management Review 14(4): 532-550.

Emiliani, B. (2008). Practical Lean Leadership: A Strategic Leadership Guide for Executives. Wethersfield, CT: The Center for Lean Business Management.

Emiliani, M. (1998). "Lean behaviors." Management Decision 36(9): 615-631.

Emiliani, M. (2003). "Linking leaders' beliefs to their behaviors and competencies." Management Decision 41(9): 893-910.

Fillingham, D. (2007). "Can lean save lives?" Leadership in Health Services 20(4): 231-241.

Flinchbaugh, J., A. Carlino and M. L. Curtis-Hendiey (2008). "Essentials of lean leadership." Tooling and Production 74(2): 16-18.

Found, P. and R. Harvey (2007). "Leading the lean enterprise." Engineering Management Journal 17(1): 40-43.

Greenleaf, R. K. and L. C. Spears (2002). Servant Leadership: A Journey into the Nature of Legitimate Power and Greatness. New York: Paulist Press.

Hines, P., P. Found, G. Griffiths and R. Harrison (2008). Staying Lean: Thriving Not Just Surviving. Cardiff, Lean Enterprise Research Centre.

Hines, P., M. Holweg and N. Rich (2004). "Learning to evolve: a review of contemporary lean thinking." International Journal of Operations \& Production Management 24(10): 994-1011.

Kotter, J. P. (1990). A Force for Change: How Leadership Differs from Management. New York: Free Press.

Krafcik, J. (1988). "Triumph of the Lean Production System." Sloan Management Review 30(1): 41-52.

Kvale, S. (1996). InterViews. An Introduction to Qualitative Research Interviewing. Thousand Oaks, CA: Sage Publications.

Lewis, M. A. (2000). "Lean production and sustainable competitive advantage." International Journal of Operations \& Production Management 20(8): 959-978.

Liker, J. (2004). The Toyota Way: 14 Management Principles from the World's Greatest Manufacturer. New York: McGraw-Hill.

Liker, J. and G. L. Convis (2011). The Toyota Way To Lean Leadership: Achieving and Sustaining Excellence Through Leadership Development. New York: McGraw-Hill.

Lummus, R. R., R. J. Vokurka and B. Rodeghiero (2006). "Improving quality through value stream mapping: a case study of a physician's clinic." Total Quality Management 17(8): 1063-1075. 
Mann, D. (2005). Creating a Lean Culture: Tools to Sustain Lean Conversions. Portland, OR: Productivity Press.

Mann, D. (2009). "The Missing Link: Lean Leadership." Frontiers of Health Services Management 26(1): 15-26.

McDonald, S. (2005). "Studying actions in context: a qualitative shadowing method for organizational research." Qualitative Research 5(4): 455-473.

Merriam, S. B. (1998). Qualitative Research and Case Study Applications in Education. San Francisco: Jossey-Bass.

Miller, D. (2005). Going Lean in Health Care. Cambridge, Institute for Healthcare Improvement: 1-24.

Northouse, P. G. (1997). Leadership: Theory and Practice. Thousand Oaks, CA: Sage Publications.

Ohno, T. (1988). Toyota Production System: Beyond Large-Scale Production. Portland, OR: Productivity Press.

Pettersen, J. (2009). "Defining lean production: some conceptual and practical issues." The TQM Journal 21(2): 127-142.

Schein, E. (2010). Organizational Culture and Leadership. San Francisco: Jossey-Bass.

Shah, R. and P. Ward (2007). "Defining and developing measures of lean production." Journal of Operations Management 25(4): 785-805.

Shiba, S., A. Graham and D. Walden (1993). A New American TQM. Portland, OR: Productivity Press.

Spear, S. J. (2004). "Learning to Lead at Toyota." Harvard Business Review 82(5): 78-86.

Stewart, G. L. and C. C. Manz (1995). "Leadership for self-managing work teams: A typology and integrative model." Human Relations 48(7): 747-770.

Stone, A. G., R. F. Russell and K. Patterson (2004). "Transformational versus servant leadership: A difference in leader focus." Leadership \& Organization Development Journal 25(4): 349-361.

Suarez-Barraza, M. F., T. Smith and S. M. Dahlgaard-Park (2012). "Lean Service: A literature analysis and classification." Total Quality Management \& Business Excellence 23(3-4): 359-380.

Sugimori, Y., K. Kusunoki, F. Cho and S. Uchikawa (1977). "Toyota production system and kanban system materialization of just-in-time and respect-for-human system." International Journal of Production Research 15(6): 553-564.

Williams, H. M., S. K. Parker and N. Turner (2010). "Proactively performing teams: The role of work design, transformational leadership, and team composition." Journal of Occupational and Organizational Psychology 83(2): 301-324.

Womack, J. and D. Jones (1996). Lean Thinking: Banish Waste and Create Wealth in Your Corporation. New York: Simon \& Schuster. 
Womack, J., D. Jones and D. Roos (1990). The Machine that Changed the World: The Story of Lean Production. New York: Rawson Associates.

Yukl, G. (1997). Leadership in Organizations. New York: Prentice-Hall. 